\title{
ESTRATÉGIAS DE APRENDIZAGEM UTILIZADAS NO ENSINO DA NATAÇÃO PARA AUTISTAS
}

\author{
LEARNING STRATEGIES USED INTEACHING SWIMMING FOR AUTISTS \\ ESTRATEGIAS DE APRENDIZAJE UTILIZADAS EN LA ENSEÑANZA DE LA \\ NATACIÓN PARA AUTISTAS
}

\author{
Estefânia do Nascimento Soares * \\ estefania2005ns@hotmail.com \\ Victor Hugo do Rosario * \\ rosariovictorhugo@gmail.com \\ Carlos Antônio Pereira da Silva ** \\ profcp@ig.com.br \\ Felipe da Silva Triani * \\ felipetriani@gmail.com
}

\author{
* Faculdade Gama Souza, Rio de Janeiro, RJ - Brasil \\ ** Universidade do Grande Rio, Duque de Caxias, RJ - Brasil
}

\section{Resumo}

O transtorno do aspecto autista é uma patologia complexa presente na sociedade contemporânea. Dada a complexidade, há dificuldade de relacionamento, principalmente no que tange ao ensino da atividade física. Além disso, poucos são os estudos acerca dessa temática, principalmente no que concerne ao meio liquido. Portanto, o objetivo é descrever e analisar as estratégias utilizadas por uma professora de natação frente a um aluno portador de transtorno do espectro autista. Trata-se de uma pesquisa do tipo relato de experiência com abordagem qualitativa. Os resultados apontam que o trabalho repetido e a estimulação contínua são fatores que contribuirão para o progresso e evolução da criança autista, além de um trabalho em conjunto dos familiares e de outros especialistas para melhor evolução do seu nível pessoal e social. A conclusão foi que o ensino inclusivo na prática da natação deverá estar preparado para que os alunos com autismo possam se desenvolver como cidadãos.

Palavras-chave: Atividades Aquáticas; Deficiência; Ensino.

\begin{abstract}
Autistic aspect disorder is a complex pathology present in contemporary society. Given the complexity, there is a difficult relationship, especially regarding the teaching of physical activity. Moreover, there are few studies on this subject, especially with regard to the liquid medium. Therefore, the objective is to describe and analyze the strategies used by a swimming teacher in front of a student with autism spectrum disorder. It is a research report of the type of experience with a qualitative approach. The results indicate that repeated work and continuous stimulation are factors that will contribute to the progress and evolution of the autistic child, as well as working together with family members and other specialists to improve their personal and social level. Inclusive teaching in swimming should be prepared so that students with autism can develop as citizens.
\end{abstract}

Keywords: Aquatic Activities; Deficiency; Teaching.

\section{Resumen}

El trastorno del aspecto autista es una patología compleja presente en la sociedad contemporánea. Dada la complejidad, hay dificultad de relación, principalmente en lo que se refiere a la enseñanza de la actividad física. Además, pocos son los estudios acerca de esta temática, principalmente en lo que concierne al medio líquido. Por lo tanto, el objetivo es describir y analizar las estrategias utilizadas por una profesora de natación frente a un alumno portador de trastorno del espectro autista. Se trata de una investigación del tipo relato de experiencia con abordaje cualitativo. Los resultados apuntan que el trabajo repetido y la estimulación continua son factores que contribuirá al progreso y evolución del niño autista, además de un trabajo en conjunto de los familiares y otros especialistas para una mejor evolución de su nivel personal y social. la enseñanza inclusiva en la práctica de la natación deberá estar preparada para que los alumnos con autismo puedan desarrollarse como ciudadanos.

Palabras clave: Actividades acuáticas; Deficiencia; Enseñanza. 


\section{Soares et al.}

\section{INTRODUÇÃO}

A natação muito se desenvolveu e se aprimorou ao longo do tempo, adequando-se aos objetivos e à evolução de seus praticantes, sendo escolhida, principalmente, como uma prática de lazer e divertimento (TAHARA, 2007). Atualmente, a natação é utilizada com objetivos terapêuticos quando utilizada no tratamento e na prevenção de enfermidades, ou no âmago esportivo, tendo como finalidade a formação de atletas, utilitários, haja vista a importância da correta locomoção na água, a fim de garantir a sobrevivência quando localizada nesse meio recreativo, visando a ludicidade e o entretenimento (ROHLFS, 1999).

O autismo é um transtorno complexo do desenvolvimento que envolve atrasos e comprometimentos nas áreas de interação social e linguagem, incluindo uma ampla gama de sintomas emocionais, cognitivos, motores e sensoriais (GREENSPAN; WIEDER, 2006). Sendo assim, o autismo passa a se constituir sob conceito heterogêneo, incluindo múltiplos sintomas, com variedades de manifestações clínicas, bem como uma ampla gama de níveis de desenvolvimento e funcionamento (KAMP-BECKER et al., 2010).

Assim, Campion (2000) admite que a atividade aquática é um modo de estimular o desenvolvimento e aumentar a experiência de movimento das crianças. A intervenção em meio aquático tem sido defendida por diversos autores como forma de promover e acompanhar o desenvolvimento global da criança, particularmente no desenvolvimento psicomotor, percetivomotor, afetivo e social. Também, Campion (2000) afirma que a atividade aquática seja um modo de estimular o desenvolvimento e aumentar a experiência de movimento das crianças.

Best e Jones, citado por Yilmaz (2004), realizaram um estudo em que se confirmou que as crianças com autismo têm capacidade de evoluir no processo de aprendizagem da natação com técnicas alternadas. Comprovaram que aprender a nadar é também um processo de aprendizagem de socialização, com melhorias observáveis no humor, em nível motor, na autoestima e na motivação. O processo de aprendizagem da natação traduziu-se numa disciplina passível de ser ensinada e assimilada por indivíduos com autismo, e converteu-se num excelente instrumento para estimular a atenção, a imitação, a autonomia, a disposição para a aprendizagem, o seguimento de ordens e a sociabilização.

Através dos seus estudos, Miranda (2011) chegou às seguintes conclusões na sua tese de mestrado: com a natação, aprende-se a respirar, desenvolvem os limites no meio líquido, melhora a lateralidade, a coordenação motora e é um agente facilitador no processo de socialização da criança autista; as crianças autistas foram capazes de executar ações motoras intencionais usando a 
propulsão da água; o meio aquático é facilitador e promotor do desenvolvimento da cognição, que favorece aspetos relacionados com a comunicação e, consequentemente, estimula a aquisição da linguagem, a melhoria do humor que é altamente significativo; a natação é um ambiente facilitador e harmonioso que oferece a possibilidade de descarregar as tensões psíquicas através do poder de relaxamento da água, ao satisfazer as necessidades de movimento.

Visto que o aluno autista em questão era uma criança, que possuía dificuldades de atenção, execução de movimentos, algumas crises durante as aulas, tinha dificuldades de se socializar com outras crianças e a professoras tinham que executar um trabalho diferenciado para ela. Sendo assim, questiona-se: quais eram as dificuldades da professora perante o aluno autista? Como as outras crianças reagiam diante de um aluno autista? Como o autista se portava durante as aulas? Diante desses entendimentos, o objetivo do presente manuscrito é descrever e analisar as estratégias utilizadas por uma professora de natação frente a um aluno autista.

\section{CONCEPÇÕES TEÓRICAS}

Toda essa visão e essa atuação do processo de aprendizagem do autista na natação vem acompanhada de uma retrospectiva acerca da historicidade do conceito de pessoas com necessidades especiais em um enfoque legal. Inicialmente, tem-se a Declaração Universal dos Direitos Humanos, de 1948, que surgiu pós Segunda Guerra Mundial, após cerca de 6 milhões de judeus serem mortos em câmaras de gás, e, em seguida, centenas de pessoas mutilidas voltavam aos seus países com algum tipo de deficiência ocasionada pelas atrocidades da luta bélica. A Declaração nasce de uma necessidade de os governos desses países protegerem todos os cidadãos contra novas atrocidades, garantindo-lhes o direito fundamental à vida.

Ainda sobre a proteção ao indivíduo e, especificamente, à criança, tem-se a Convenção do Direito da Criança, de 20 de novembro de 1989, em que a República Federativa do Brasil ratifica em 1990, o que vem a insurgir na solidificação do Estatuto da Criança e do Adolescente, no Brasil, Lei 8.069 de 13 de julho de 1990. Mas é a Declaração de Salamanca, de 1994, na Espanha, resultante da Conferência Mundial sobre Necessidades Especiais que vem a promover uma educação igualitária para todas as crianças, principalmente àquelas com necessidades especiais. Essa Declaração visa um trabalho pedagógico centralizado na criança. De uma forma direta ao processo de ensino-aprendizagem, é descrito no texto da Declaração que toda criança tem direito fundamental à educação, em que a educação inclusiva deve ser construída sob forma de lei ou de políticas públicas. 
Corrêa (2010) apresenta algumas características presentes no texto dessa Declaração que é o marco para o surgimento de outros dispositivos legais que protegem os direitos das crianças com necessidades especiais, principalmente no Brasil: o direito de a criança manifestar seus desejos quanto ao processo educacional que lhe é oportunizado; as escolas tem o dever de acolher todas as crianças, independentemente de suas condições físicas, emocionais, intelectuais etc, inclusive acolher, de forma afetiva, as crianças que necessitam de cuidados especiais e, inclusive, grupos minoritários quanto à etnia, a culturas; a escola deve ser integradora, desenvolvendo um trabalho pedagógico centralizado na criança, e a aprendizagem deve estar vinculada às necessidades da criança, e não a criança sob o absoluto dever de atender aos preceitos regulares da proposta de ensino apresentada.

Embora essas características estejam pareçam estar ligadas diretamente a uma educação escolar construídas em formalidades do processo de educar em sala de aula, mas a aprendizagem se dá em todo o espaço onde se possa socializar, integrar a criança à educação de qualidade. Assim, o professor de educação física, seja em atuação em clube, academias ou escolas, ele também é um sujeito responsável por construir essa inclusão com a criança com necessidades especiais.

A Constituição da República Federativa do Brasil de 1988, enseja em seu texto diversos artigos atinentes à Educação Especial:

a) Capítulo II - Da União

Art. 23 - É competência comum da União, dos Estados, do Distrito Federal e dos Municípios: II - cuidar da saúde e assistência pública, da proteção e garantia das pessoas portadoras de deficiência.

Esse artigo é concretizado pela Lei Complementar 10.048 de 08 de novembro de 2000, que dá garantia aos portadores de deficiências, idosos e gestantes um atendimento prioritário, obrigando a todas as empresas, inclusive públicas, a oferecerem esse tipo de atendimento. Outro dispositivo legal garantido pela norma constitucional ainda nesse artigo é a Lei Complementar 10.098 que garante critérios para promoção à acessibilidade das pessoas com mobilidade reduzida, e o outro dispositivo é a Lei Complementar 7853 de 1989 que dispõe sobre o apoio e a integração à sociedade das pessoas com algumas deficiências.

b) Capítulo III - Da educação, da cultura e do desporto

Seção I - Da educação

Art. 205 . A educação, direito de todos e dever do Estado e da família, será promovida e incentivada com a colaboração da sociedade, visando ao pleno desenvolvimento da pessoa, seu preparo para o exercício da cidadania e sua qualificação para o trabalho. 
Aqui, tem-se a Lei de Diretrizes e Bases da Educação Nacional, lei 9.394 de 20 de dezembro de 1996, em que cita a educação como gratuita dos quatro aos dezessete anos de idade, da préescola ao ensino-médio.

Art. 208. O dever do Estado com a educação será efetivado mediante à garantia de:

III. atendimento educacional especializado aos portadores de deficiência, preferencialmente na rede regular de ensino.

Também presente na Lei 9.394 de 1996, com a mudança na Lei 12.796 de 2013 que trata do atendimento educacional especializado gratuito aos educando com deficiência, transtornos globais do desenvolvimento e altas habilidade etc.

Outros dispositivos constitucionais explicitam sobre pessoas com deficiências, como os dos Direitos e Garantias Fundamentais presentes no Art. $7^{\circ}$, que hoje devem ser identificadas como portadoras de necessidades especiais, uma vez que essa denominação traz ao Estado e à sociedade a obrigatoriedade de todos interagirem, Estado e sociedade, em prol de uma uniformidade de convívio social, independente das dificuldades motoras, intelectuais e comportamentais. Porém, a legislação mais recente, como Lei Complementar, é a Lei 13.146 de 13 de julho de 2015, o Estatuto da Pessoa com Deficiência. Esse Estatuto, em seu Capítulo IX enfatiza o direito da pessoa com deficiência à Cultura, ao Esporte, ao Turismo e ao Lazer, assegurando, assim, vários princípios que norteiam a participam desses cidadãos nas diversas atividades culturais e esportivas, como o Princípio da Integração, sob valores de igualdade; Princípio de Legitimidade, como participação de todos na realização de leis que possam direcionar a ações de uniformização social de todos no meio em que estão inseridos; Princípio da Dignidade Humana, como viés de respeito às diferenças como igualdade entre todos.

Nesse contexto de conhecimento da historicidade de algumas legislações, o professor de Educação Física pode se inserir numa seara de conceitos e descobertas que sejam direcionadas a melhor reflexão de suas atitudes como profissional da Educação, pois ele terá, em todos os campos em que possa atuar, cidadãos, crianças com necessidades especiais, principalmente, que querem participar de atividades recreativas, lúdicas e esportivas, a fim de que possam fazer parte de uma comunidade com os mesmo objetivos e vontades. Depois do conhecimento teórico, o trabalho com crianças autistas é uma forma pragmática de conhecer as diferentes pessoas em um trabalho que visa o bem comum, a vida com qualidade, com respeito e dignidade ao próximo, podendo o profissional da educação física fazer parte de uma equipe interdisciplinar na busca de meios e resultados que possam auxiliar a criança com necessidades especiais à inclusão no espaço social. E a prática esportiva, promovida pelo professor de educação física, auxilia a autoestima, a Revista Valore,Volta Redonda, 2 (2): 316-328,Ago./Dez. 2017 
autoconfiança do autista, como também promove a interação com outras pessoas, e a natação, de forma individual ou coletiva, trabalha a confiança e a determinação dessas crianças.

Orrú (2011) bem conceitua autismo. Segundo a autora, essa palavra é de origem grega (autós) que significa "por si mesmo”, ou seja, esse vocábulo, usado na ciência psiquiátrica, dirige-se aos comportamentos do homem que se referem ao próprio individuo. Não sendo uma doença, mas sim uma síndrome, ou seja, um conjunto de sinais e sintomas que, em conjunto, constituem uma “doença”. Assim, para o educador, é preciso que reconheça alguns comportamentos das crianças autistas a fim de que possa direcionar seu plano de atividades em prol de resultados positivos de interação e sociabilidade. Adiante, o estudo de caso concretizará para o que, até esse momento, foi apresentado nesse texto introdutório.

\section{METODOLOGIA}

Este estudo tem como metodologia o estudo de caso que, de acordo com Gil (2016) é uma modalidade de pesquisa amplamente utilizada nas ciências biomédicas e sociais. Consiste no estudo profundo e exaustivo de um ou poucos objetos, de maneira que permita ser amplo e detalhado.

A pesquisa foi realizada em um parque aquático de uma academia na Barra da Tijuca, em uma piscina de aproximadamente doze metros e meio de comprimento, aquecida, e possui um metro e quarenta de profundidade. A piscina possui uma escada em um dos cantos e tem uma plataforma em cada extremidade da borda, para que as crianças consigam ficar de pé sem nenhuma dificuldade; possui, ainda, diversos materiais para o uso nas aulas de natação, como: brinquedos, colchões, pranchas, macarrões, flutuadores, bambolê, escorrega, bóias, arcos e tapetões.

O autista é uma criança de dez anos, do sexo masculino, que possui algumas vezes mudanças de temperamento. Quando calmo, é uma criança que faz as atividades, no seu tempo, sempre precisando de ajuda para executar; quando entra em crise, essa criança é mais agitada, costuma gritar e empurrar a professora, e, na maioria das vezes, não faz as atividades que são propostas. Em casos de crises extremas, em que a professora já não tem mais alternativa para acalmá-la, a criança é retirada da piscina.

O período em que estive observando o autista foi em meados de janeiro até março, foi quando usei um diário de relatórios, para anotações das atividades e atitudes físicas e emocionais. Os relatórios eram feitos diariamente, pois o aluno costumava a ir às aulas duas vezes por semana. 
Nos períodos de observação, estive ao lado de uma professora, ajudando-a a executar a aula, pois a criança autista sempre precisava de mais ajuda, por fatores como: falta de atenção, crises de humor, e/ou dificuldades de executar propriamente dito a atividade proposta.

\section{ALGUNS APONTAMENTOS INICIAIS: DESAFIOS E PERSPECTIVAS}

Embora seja um desafio ensinar a natação para um autista, é importante destacar a sua inclusão, pois todos têm o direito de fazer ou praticar qualquer coisa dentro de suas limitações. Neste relato vamos ver as estratégias de uma professora para a inclusão desse aluno autista.

Depois que ingressei como estagiária em uma academia, tive uma experiência com um portador de autismo praticante de natação. Os momentos na qual tive um contato direto com esse aluno foi apenas observatório, pois ele não costumava aceitar algumas pessoas ao seu lado. Sobre isso, Hanson (1989) diz que as crianças com autismo apresentam falhas constitucionais nos componentes de ação e reações, necessários para o desenvolvimento das relações que envolvem afeto com as outras pessoas; existem, contudo, déficits na capacidade de abstrair, sentir e pensar simbolicamente. Acredita-se que a habilidade inata do ser humano em se relacionar emocionalmente e socialmente com outras pessoas está ausente nas crianças que desenvolvem o autismo (HANSON, 2002). Crianças com autismo têm dificuldades em regular a interação social e a comunicação, por seus comportamentos, tendo muitas vezes nenhum interesse em estabelecer relações sociais, com diferentes níveis de dificuldades na reciprocidade social e emocional (GÓMEZ; TORRES; ARES, 2009; NOGUEIRA, 2009).

Essa criança tem 10 anos e foi incluso em uma turma de natação. Junto com ela, ainda, tem mais duas crianças que não são portadoras do autismo, portanto existe mais um trabalho por traz, para que as outras crianças aceitem bem o convívio com outro aluno, que aos olhos deles é diferente. Sobre essa interação, Wing e Gould (1979) confirma a existência de três estilos de interação social para autistas, a saber: distante, passivo e ativo (mais singular na atividade). O primeiro trata-se de crianças distantes, isolam-se do contato social, aborrecem-se quando perto de outras pessoas e geralmente rejeitam propostas sociais. Em contraste, as crianças do grupo passivo embora não tomem iniciativas sociais, aceitam tais iniciativas por outros sem demonstrarem aborrecimentos e podem até mesmo apreciar tal contato social. O ultimo grupo é composto por indivíduos que se aproximam espontaneamente das pessoas, mas o fazem de maneira incomum, unilateral e inapropriada. Esse grupo demonstra frequentemente um nível mais elevado de competência geral que os outros grupos. 
O autismo afeta a maneira como uma criança se desenvolve e responde ao ambiente, tanto no espaço físico, quanto na relação com objetos, eventos, lugares, e principalmente no contato interpessoal e social. Essas alterações de afetividade ocasionam interferências na aprendizagem cultural e no compartilhar de experiências do "senso comum" do mundo (TREVARTHED; DANIEL, 2005). Nesse sentido, foi possível perceber esse apontamento quando a criança portadora do autismo ia para a natação, o que não era com grande frequência, a professora era quem passava a maior parte do tempo ao lado dele, pois o mesmo perdia o foco com muita facilidade, então ele precisava de uma atenção a mais, para que ele estivesse mais presente nas aulas.

No que tange aos problemas de atenção das crianças com autismo, é fundamental saber que seu foco esteja em aspectos estreitos do ambiente, porque têm dificuldade para integrar a percepção ou extrair significado de padrões de estímulos "complicados"; assim, elas atentam para estímulos de natureza mais simples (MESIBOV et al., 1997).

\section{O PROCESSO DE INTERVENÇÃO: APRENDENDO NA PRÁTICA}

A intervenção no autismo basicamente é educacional, devendo recorrer-se a estratégias comportamentais e terapias diretas que devem ser do conhecimento da família. (OLIVEIRA, 2009). Assim, é fundamental que, com crianças autistas, sejam implementadas estratégias, em fases precoces do desenvolvimento, que promovam o desenvolvimento das dificuldades, através da brincadeira e do jogo, que constituem um dos melhores meios para as crianças aprenderem (WALL, 2010).

Quando se trabalha com crianças autistas, e se planejam os programas de intervenção junto das mesmas, estes fatores deverão ser inseridos no processo de inclusão: uma intervenção precoce; uma parceria próxima e eficaz com os pais e outros profissionais; estrutura e rotina para a criança; a utilização de pistas visuais para apoiar a criança; a utilização de sistemas de comunicação alternativos; a inclusão de momentos de aprendizagem; observação regular; consciência das questões (ou possíveis dificuldades) sensoriais; ter em consideração as preferências e forças da criança, assim como as suas dificuldades; e a utilização de estratégias específicas de ensino a autistas (WALL, 2010).

Sobre as aulas, elas eram bastante dinâmicas, o uso do material e a forma como era explicada o exercício era de uma forma geral bastante satisfatória, o uso do macarrão, prancha, argolas, tapete, entre outros materiais, cada um tinha uma forma de ser apresentando, para chamar a atenção e se torna algo atrativo. As argolas, por exemplo, era uma atividade chamada como caça ao 
tesouro, fazendo com que o aluno vá buscar a argola na mão da professora ou no fundo da piscina, tudo dentro dos limites de cada aluno. As cores dos materiais também são estratégias para chamar a atenção.

Essa criança teve alguns momentos de crise: gritava bastante, empurrava a professora e se recusava a fazer qualquer exercício que era proposto. A professora, por sua vez, tentava de uma maneira amigável conversar com o aluno, enquanto eu, como estagiária, continuava a aula para os outros alunos, tentando da melhor maneira atrair a atenção para mim, enquanto a professora tentava acalmá-lo.

Analisando de uma forma geral, a professora conseguia contornar aquela situação apenas com uma conversa, passando serenidade e calma, fazendo com que a criança portadora do autismo ficasse mais calma. Para que o professor promova o desenvolvimento cognitivo e, consequentemente, a modificabilidade cognitiva estrutural do aluno, a interação deve seguir alguns princípios ou critérios básicos. De acordo com Tzuriel (1999, 2001), Klein (1996) e Feuerstein e Feuerstein (1991), podem ser indicados pelos menos três componentes de mediação principais: a intencionalidade, a significação e a transcendência.

A intencionalidade ocorre quando um mediador intencionalmente chama a atenção da criança para um objeto e ela responde a esse estímulo, sendo um elemento fundamental no processo de aprendizagem mediada, uma vez que cria na criança um estado de alerta e desenvolve nela a capacidade de realizar um registro eficiente das informações e um processamento mental adequado, além de apresentar uma resposta eficiente (TZURIEL, 1999).

Já a significação se refere ao comportamento do mediador em enfatizar a importância de um estímulo, por meio da expressão de afeto e pela indicação do valor e significado do mesmo, quando a criança aprende o significado dos estímulos em uma situação de aprendizagem mediada e internaliza esse processo, passando, mais tarde, espontaneamente, a buscar o significado de novas informações. (CUNHA, 2003; CUNHA, 2004).

E ainda, a transcendência que diz respeito à generalização da aprendizagem de regras, estratégias e princípios; refere-se à atitude do mediador em conduzir a criança para além de contextos concretos, com objetivo de ela transferir a aprendizagem de princípios gerais e objetivos para situações e/ou contexto específicos (CUNHA, 2003; CUNHA, 2004).

Não se deve encarar a natação como simplesmente técnicas de nado, pois ela engloba muito mais do que isso. Há a preocupação da adaptação ao meio liquido, o desenvolvimento motor de maneira lúdica, os nados de sobrevivência, além do conhecimento corporal. O trabalho feito com o autista precisa ter o objetivo de desenvolver o máximo a independência da criança. 


\section{CONSIDERAÇÕES FINAIS}

Como é sabido, as crianças autistas apresentam dificuldades em nível da comunicação e da socialização. O ensino inclusivo, na prática do esporte, deverá estar preparado para que os alunos com autismo e/ou com necessidades educativas especiais possam se desenvolver como cidadãos, assim como deve estar preparado para que possam adquirir novas competências.

A partir do caso em questão, percebeu-se como fundamental no processo de intervenção a promoção do desenvolvimento global do aluno e de competências específicas; informar e auxiliar os encarregados de educação para inserir estratégias para intervenção; informar/sensibilizar acerca das características da criança e/ou jovem, no sentido de estabelecer parcerias que contribuam para a sua aprendizagem, adaptação e inclusão social.

Portanto, é necessário que os professores estejam preparados para trabalhar com esse tipo de alunos. Os conceitos a abordar devem ser repetidos várias vezes e sempre da mesma maneira. Contudo, deve-se inovar e variar sempre que possível. Qualquer professor necessitará de bastante paciência para trabalhar com uma criança autista, devendo aceitar e reconhecer as suas "limitações" e respeitar seu próprio tempo, por isso dever-se-á trabalhar com a criança autista por etapas.

O trabalho repetido e a estimulação contínua são outros fatores que contribuirão para o progresso e evolução das capacidades da criança autista sob o foco pessoal e social. Em suma, há que procurar compreender os comportamentos autistas e estipular objetivos a atingir, estimulando e acompanhando a criança/jovem no seu processo de desenvolvimento e de aprendizagem, e contribuindo para a sua integração plena na sociedade.

Hoje, o autismo é uma doença debilitante, o comprometimento dos autistas é tão complexo, que é difícil propor um tratamento que seja plenamente satisfatório e que funcione em todos os casos. O que parece verdadeiro e indiscutível é que essas crianças são tão especiais que necessitam de uma equipe de profissionais de várias áreas que trabalhem conjuntamente para proporcionar, a elas e aos seus familiares, uma convivência com o mundo mais aceitável. 


\section{Referências}

BRASIL. Constituição da República Federativa do

Brasil. Disponível em $:<$ http:

//www.planalto.gov.br>. Acesso em 17 jul. 2017.

BRASIL. Declaração de Salamanca. Disponível em

http://portal.mec.gov.br/seesp/arquivos/pdf/salamanc

a.pdf. Acesso em 19 jul.2017.

BRASIL. Estatuto da Pessoa com Deficiência.

Disponível em: < http: www.planalto.gov.br $>$.

Acesso em 17 jul.2017.

BRASIL. Lei de Diretrizes e Bases da Educação Nacional. Disponível em: < http:// www.planalto.gov.br>. Acesso em 19 jul. 2017.

CAMPION, Margareth. Hidroterapia: princípios e prática. São Paulo: ed. Manole, 2000.

CORRÊA, Maria Angela Monteiro Corrêa. Educação Especial. V.1 . Rio de Janeiro: Fundação CECIERJ, 2010. 
Recebido em: 25/10/2017

Aceito em: 16/11/2017

Endereço para correspondência:

Nome: Estefânia do Nascimento Soares

Email: estefania2005ns@hotmail.com

cc) (7)

Esta obra está licenciada com uma Licença $\underline{\text { Creative }}$ Commons Atribuição 4.0 Internacional. 